\title{
Long Term Greenhouse Gas Emissions from the Hydroelectric Reservoir of Petit Saut (French Guiana) and Potential Impacts
}

Robert Delmas, Sandrine Richard, Frédéric Guérin, Gwénaël Abril, Corinne Galy-Lacaux, Claire Delon and Alain Grégoire

\section{Abstract}

This paper summarizes, in a first part, results of greenhouse gas emissions from the hydroelectric reservoir of Petit Saut in French Guiana obtained during the three first years after impoundment (1994-1997). Results from three years of measurements have been extrapolated to estimate trends in methane emissions and the carbon budget of the reservoir over a 20 -year period. Extrapolations were made using the global warming potential concept to calculate cumulative greenhouse gas emissions at a 100-year time horizon and to compare these emissions to potential emissions from thermal alternatives. In a second part, we analyze new data from long term continuous observations (1994-2003) of methane concentrations in the reservoir and flux data obtained during a recent campaign in May 2003. These data confirm predicted trends and show some suitable adjustments. They constitute a unique data base which is used for the development of a model to simulate both water quality and greenhouse gas emissions from tropical artificial reservoirs.

\subsection{Introduction}

Over the two last decades increasing concentrations of greenhouse gases (GHG) in the atmosphere contributing to an enhanced greenhouse effect have become a major environmental issue. The main contributor to this effect is, by far, fossil fuel combustion. Until recently, it was believed that 
hydroelectric energy was a clean energy source compared to thermal energy production, with almost no impact on the greenhouse effect. The creation of artificial lakes modifies biosphere-atmosphere exchanges on a local scale. Carbon dioxide and methane are mostly produced from organic matter decomposition under anaerobic conditions, generating a source of greenhouse gases. From theoretical considerations Gagnon and Chamberland (1993), Svensson and Ericson (1993), and Rosa and Shaeffer (1994) suggested that artificial reservoirs could constitute an anthropogenic source of greenhouse gases. This was confirmed by the first flux measurements on boreal reservoirs (Kelly et al. 1994; Duchemin et al. 1995). More recently, Fearnside (1995) calculated that some tropical reservoirs may emit more greenhouse gases than thermal power plants of equivalent power output. Field measurements conducted on Petit Saut reservoir in French Guiana, since reservoir impoundment in 1994, confirmed that tropical reservoirs can be quite a significant source of both carbon dioxide $\left(\mathrm{CO}_{2}\right)$ and methane $\left(\mathrm{CH}_{4}\right)$ (Galy-Lacaux et al. 1997). Results presented in this last paper also highlighted the influence of methane produced within the reservoir on water quality showing that methane oxidation could be responsible for high oxygen depletion in the whole hydro system, including both the reservoir and the river downstream of the dam. A recent global scale assessment of GHG emissions from reservoirs (Saint-Louis et al. 2000), suggests that artificial reservoirs, whose total area is of the order of $1500000 \mathrm{~km}^{2}$, could be a major anthropogenic source of methane representing $64 \mathrm{MT} \cdot \mathrm{y}^{-1}, 90 \%$ of emissions occurring from tropical latitudes. It is now recognized that artificial reservoirs are a GHG source, however, such global estimates are highly speculative since they rely on a very limited number of data sets. More work is clearly needed in order to better define the order of magnitude of this source and to compare it with emissions from other land surfaces, both natural (wetlands) and anthropogenic (rice paddy fields).

In this paper we first review results from the literature dealing with emission trends over 20 years from the Petit Saut reservoir (Galy-Lacaux et al. 1999). We then on a calculate, on a 100-year time scale, the net GHG emissions from this reservoir and compare the results with GHG emissions from thermal alternatives (Delmas et al. 2001). These results allow some preliminary conclusions to be drawn about hydroelectric energy and greenhouse gas emissions. The regular measurements of chemical parameters of the reservoir water column between 1997 and 2002 allow for the evaluation of the accuracy of the comparison between hydroelectric and thermal energy production. A new program was launched at the beginning of 2003 in order to reduce uncertainties pertaining to this question. This program includes new observations and modeling of which the first recent results are presented in the last section of this chapter. 


\subsection{Experimental Site and Campaigns}

\subsubsection{The Petit Saut Reservoir}

Petit Saut is a hydroelectric dam, built by Electricité de France (EDF), in the tropical forest of French Guiana on the Sinnamary river, some $60 \mathrm{~km}$ upstream of its outlet to the Atlantic $\left(5^{\circ} 03^{\prime} \mathrm{N}, 53^{\circ} 02^{\prime} \mathrm{W}\right)$ (Fig. 12.1) (Sissakian et al. 1997). Filling of the reservoir began in January 1994. The maximum depth of the reservoir $(35 \mathrm{~m})$ was reached in June 1995. This depth corresponds to the immersion of about $365 \mathrm{~km}^{2}$ of primary forest with the creation of $105 \mathrm{~km}^{2}$ of small islands (Huynh et al. 1996). The total amount of flooded biomass, including above-ground vegetation $(170 \mathrm{~T}(\mathrm{C}) / \mathrm{ha})$ and soil carbon $(100 \mathrm{~T}(\mathrm{C}) / \mathrm{ha})$ was around 10 million tons of carbon (Galy Lacaux et al. 1999). At maximum operating level the reservoir volume is close to 3500 million $\mathrm{m}^{-3}$ and the annual mean discharge of the Sinnamary river is $267 \mathrm{~m}^{3} \cdot \mathrm{s}^{-1}$. The average turnover time is estimated to be about six months. At Petit Saut four turbines provide maximum power of $115 \mathrm{MW}$ (mega Watts). For this dam the ratio between installed capacity and inundated area is therefore $0.32 \mathrm{MW} \cdot \mathrm{km}^{2}$ corresponding to about 11.5 MW per MT of carbon flooded. This ratio is two times less than the average ratio for hydroelectric reservoirs of the Amazon region (excluding Balbina dam in Brazil ).

To solve the problems of deoxygenation observed in the downstream Sinnamary during the turbining tests, resulting from oxidation of methane generated in the reservoir, a two-falls aerating weir was built in the plant outlet canal (Gosse et al. 1997). Operational since March 1995, the weir allows the power station to function continuously while guaranteeing a minimum dissolved oxygen concentration of $2 \mathrm{mg} \cdot \mathrm{L}^{-1}$ in the downstream Sinnamary and preserving fish life in the river. The weir resulted in a strong degassing of dissolved methane with close to $80 \%$ of dissolved methane in turbined water being released into the atmosphere at the weir level (Galy-Lacaux et al. 1997; see also Richard et al. Chap. 23). Such a system is specific to the Petit Saut reservoir and is not present in other hydroelectric dams in South America.

\subsubsection{Measurements}

Diffusive and bubbling fluxes of $\mathrm{CH}_{4}$ and $\mathrm{CO}_{2}$ at the reservoir surface, dissolved gas concentrations $\left(\mathrm{CH}_{4}, \mathrm{CO}_{2}\right.$ and $\left.\mathrm{O}_{2}\right)$ and profiles of physicochemical characteristics in the water column (conductivity, $\mathrm{pH}$, redox po- 


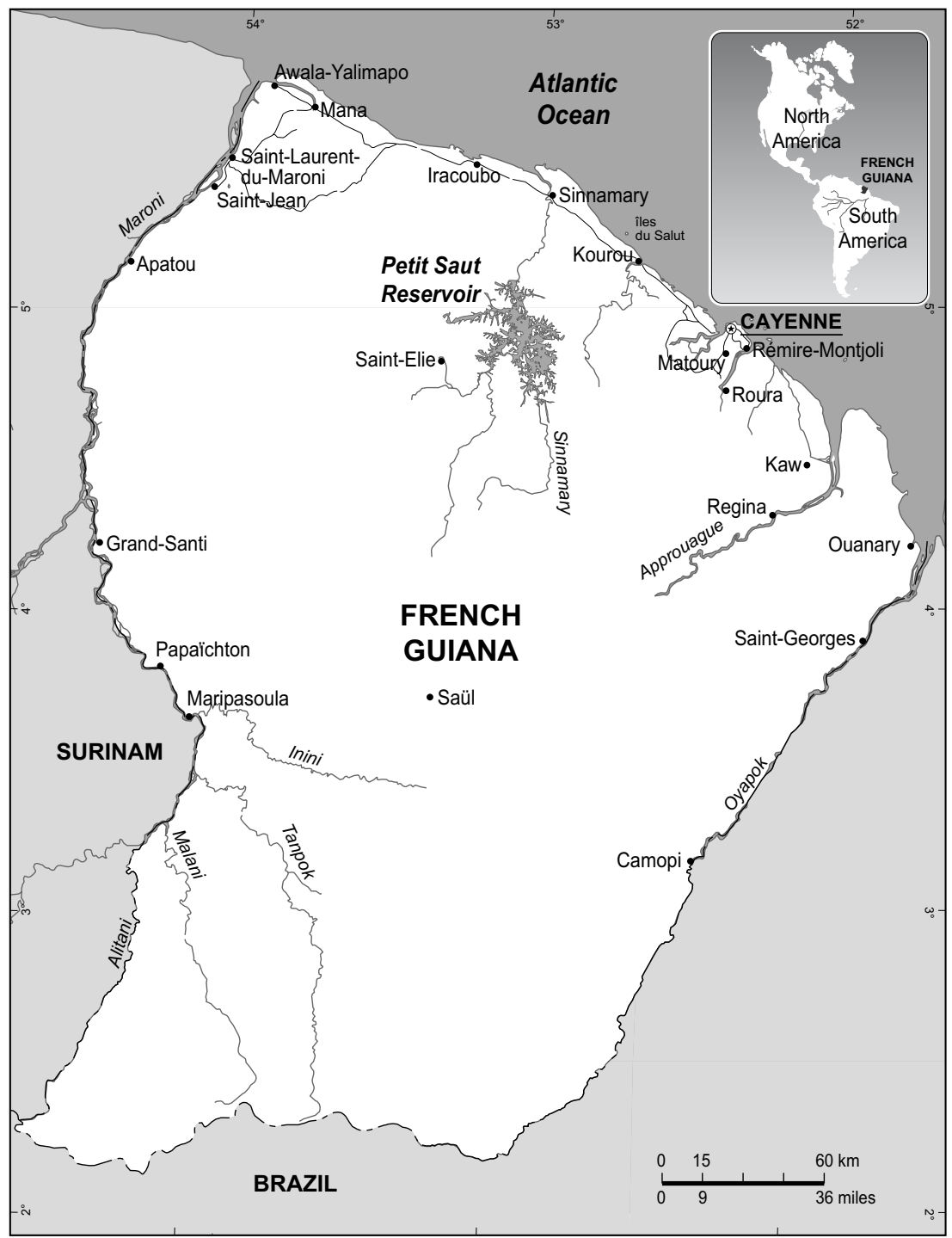

Fig. 12.1. Map of the Petit-Saut reservoir located in South America-French Guiana

tential and temperature) were measured during seven research campaigns carried out at Petit Saut between January 1994 and September 1997. An additional campaign was also conducted in 1995 on three reservoirs in the forested region of the southern Ivory Coast (Buyo, Taabo and Ayame), in order to investigate older reservoirs. Average characteristics of Petit Saut 
(water flow and residence time, type of vegetation) correspond well with those of Buyo reservoir, which started to be filled 15 years earlier (Galylacaux et al. 1999; see also Chap. 23).

Diffusive fluxes $\left(\mathrm{CH}_{4}, \mathrm{CO}_{2}\right)$ were measured using floating static chambers. Fluxes were calculated from the slope of the regression line of gas concentration in the chamber as a function of time (Delmas et al. 1992). Methane and carbon dioxide emission by bubbling were measured with a set of 12 inverted polyethylene funnels that only collect gas bubbles (Keller and Stallard, 1994). Degassing fluxes $\left(\mathrm{CH}_{4}, \mathrm{CO}_{2}\right)$ induced by the aerating weir were determined using the average concentration of dissolved gas in the reservoir water column and the daily total water flow calculated from the EDF hydrological budget. Dissolved gas concentrations were measured by the headspace technique in samples taken at various depths (MacKay and Shiu, 1981). Analyses of gas concentrations were performed by gas chromatography using a flame ionization detector for $\mathrm{CH}_{4}$ and a thermal conductivity detector for $\mathrm{CO}_{2}$. Commercial standards of various concentrations adapted to the type of measurements were used for calibration. The reproducibility of the standards for each set of analysis was greater than $95 \%$. In addition to dissolved $\mathrm{CH}_{4}$ and $\mathrm{CO}_{2}$ concentrations, probes were used to measure profiles of dissolved oxygen and other parameters (temperature, conductivity, redox potential) in the water column at each station of the reservoir.

In order to follow the long term evolution of parameters, vertical profiles of dissolved oxygen and methane concentrations were regularly measured once or twice a month at a station located on the reservoir axis, at $20 \mathrm{~km}$ from the dam since the beginning of 1998. An additional experiment was conducted in May 2003 to monitor trace gas fluxes and dissolved gas concentrations in the whole hydro-system 8 years after the filling of the reservoir.

\subsection{Results}

\subsubsection{Observed and Predicted Emissions Over 20 Years}

\section{Concentrations and Emission Trends}

The assessment of trends in emissions is based on the evolution of methane concentrations observed over three and half years after impoundment and on data collected in the Buyo reservoir in the Ivory Coast. These data suggest an expression for the time dependence of the average dissolved meth- 
ane concentration in the reservoir water column, over 20 years after impoundment:

$$
C(t)=[10.5+3.5 \cos (2 \pi / 12) t] \exp ^{-0.015 t}
$$

where $\mathrm{C}(\mathrm{t})$ is dissolved methane concentration in $\mathrm{mg} \cdot \mathrm{l}^{-1}$ and $\mathrm{t}$ the time in months. The coefficient of decrease (0.015) is chosen to make the dissolved $\mathrm{CH}_{4}$ concentration in Petit Saut reservoir, 17 years after impoundment, equal to the one measured at Buyo. The 10.5 and $3.5 \mathrm{mg} \mathrm{L}^{-1}$ amplitude coefficients were calculated by adjustment to the first three years of data taken at Petit Saut. The cosine function, with a periodicity of 12 months, describes the variations of dissolved $\mathrm{CH}_{4}$ concentrations related to annual fluctuations of the Sinnamary water flow. Expression (12.1) is shown in Fig. 12.2, together with 1994 to 1996 data from Petit Saut. A similar expression was calculated to describe the evolution of dissolved $\mathrm{CO}_{2}$, based on the relationship between $\mathrm{CH}_{4}$ and $\mathrm{CO}_{2}$ concentrations. The two parameters are linearly correlated with a regression coefficient $\mathrm{r}=$ 0.92 , and a regression line expressed as:

$$
\left(\mathrm{CO}_{2}\right)=6.11\left(\mathrm{CH}_{4}\right)+22.5(\text { Galy-Lacaux et al. 1999) }
$$

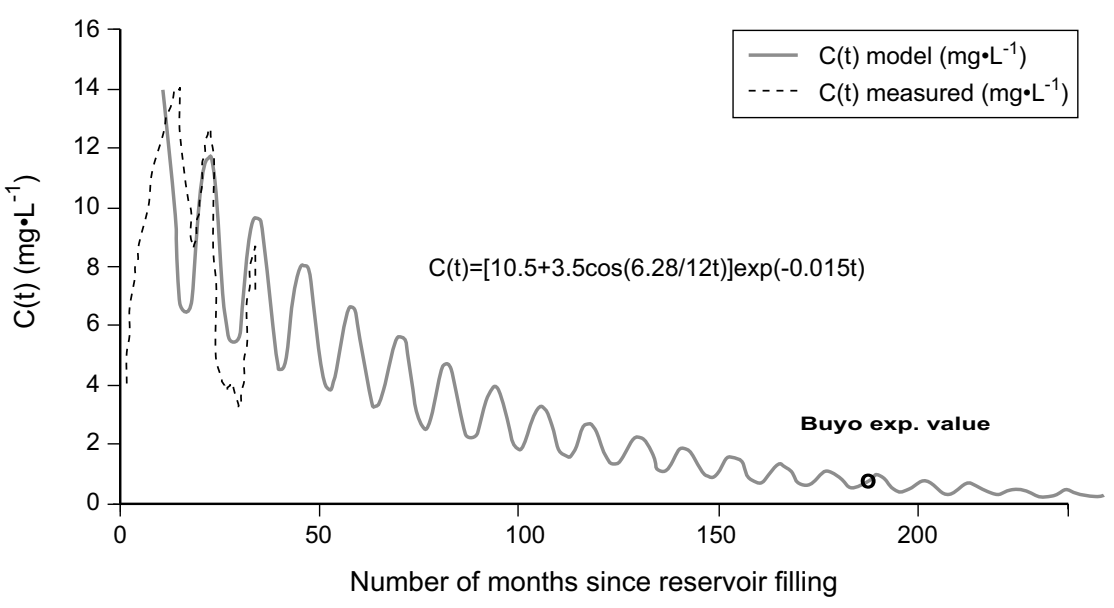

Fig. 12.2. Modeled Variations of dissolved $\mathrm{CH}_{4}$ concentrations in the Petit Saut reservoir over a 20-year period based on the three first years of measurements and data from an older reservoir with similar characteristics, in Ivory Coast (Buyo) 
Seasonal variations were shown to be linked to lake dynamics driven by rainfall variations (Galy Lacaux et al. 1999) according to the equation.

$$
\frac{d C}{d t}=\frac{P-F-L}{V}-\frac{q_{\text {in }} \cdot C}{V}
$$

$\mathrm{C}$ is the concentration of dissolved methane. The term (P-F-L) represents the sum of vertical methane fluxes throughout the reservoir (production at sediment level, diffusion at the surface, and oxidation in the water column). If we assume that vertical methane fluxes (P-F-L) do not vary dramatically over time; then Eq. 12.3 shows that temporal variations of methane concentrations are primarily determined by the reservoir inflow $\left(\mathrm{q}_{\text {in }}\right)$. The term $\left(\mathrm{q}_{\mathrm{in}} . \mathrm{C}\right) / \mathrm{V}$ introduces a dilution term directly proportional to $\mathrm{q}_{\mathrm{in}}$ that explains most of the seasonal variations in the concentration of dissolved gases.

Greenhouse gas emissions from the Petit Saut reservoir result from three distinct processes: diffusion at the lake surface, bubbling in shallow zones (with water depth less than $10 \mathrm{~m}$ ), and degassing of turbined water by the aerating weir.

Following a sharp increase immediately after the beginning of impoundment, the diffusive flux of methane at the lake surface dramatically decreased about one year later as a consequence of methanotrophic bacterial community development at the oxycline level. Bacteria were shown to be inhibited by light as long as the oxycline was very close to the surface (Dumestre et al. 1999). As a consequence the methane concentrations between the surface and the oxycline are depleted compared with those observed in the anoxic epilimnion. The diffusive flux was maximum (up to $3 \mathrm{~g} \cdot \mathrm{m}^{-2} \cdot \mathrm{d}^{-1}$ ) within the first year of reservoir filling, then it rapidly decreased, due to methane oxidation at the oxycline level, down to values of the order of a few $\mathrm{mg} \cdot \mathrm{m}^{-2} \cdot \mathrm{d}^{-1}$. To extrapolate diffusive emissions over a 20 -year period, we assign a sharp decrease in emission rates after the second year and a flux equal to zero 5 years after impoundment. The emissions decrease from $35 \mathrm{Gg}\left(\mathrm{CH}_{4}\right)$ during the first year after impoundment to zero 5 years later (Fig. 12.2). Emission from gas bubbles is difficult to assess since measurements are only available for the first and the fourth year after impounding. In 1994, bubbling emission from the whole reservoir was estimated, from a limited data set, to be in the order of $120 \mathrm{mg} \cdot \mathrm{CH}_{4} \cdot \mathrm{d}^{-1}$. In 1997 , based on a significant number of measurements, the same estimate provides a value a factor of 10 lower $\left(12.7 \mathrm{mg} \cdot \mathrm{CH}_{4} \cdot \mathrm{d}^{-1}\right)$. We do not have information on the long term evolution of methane emissions from gas bubbles by such reservoirs. However, results from the Ga- 
tun Lake in Panama (Keller and Stallard, 1994) suggest that this type of emission may persist over time.

Emission from water degassing downstream of the dam is the most important term of the global methane flux from this hydrological system. About $80 \%$ of dissolved methane in evacuated water is emitted into the atmosphere by water degassing downstream of the dam. This emission has taken place since March 1995, when an aerating weir was built in the plant outlet canal in order to eliminate methane from the water and, therefore, prevent the oxygen consumption by methane oxidation in the river (P. Gosse 1994; P. Gosse et al. 1997). The remaining methane fraction is, for a major part, biologically oxidized along the river course (Galy-Lacaux et al. 1997; Richard et al. Chap. 23). Methane concentrations higher than $3000 \mathrm{ppm}$ were measured in the air plume produced by the water fall. Compared with the two other emission mechanisms, gas emission from water degassing only depends on the average dissolved methane concentration in the water column and on the water outflow. The assessment of long term variations of emission from degassing is therefore easier to quantify. The variation in degassing flux over 20 years, shown in Fig. 12.3, is calculated from the analytical algorithm representing the evolution of dissolved methane concentration over 20 years and from a theoretical variation of the Sinnamary river flow. The water degassing flux is clearly dominant in overall methane emission from the reservoir. This is a typical feature of reservoirs in comparison with natural lakes or wetlands. In the particular case of the Petit Saut reservoir, this flux takes place in the near downstream of the dam, due to the presence of the artificial overflow weir

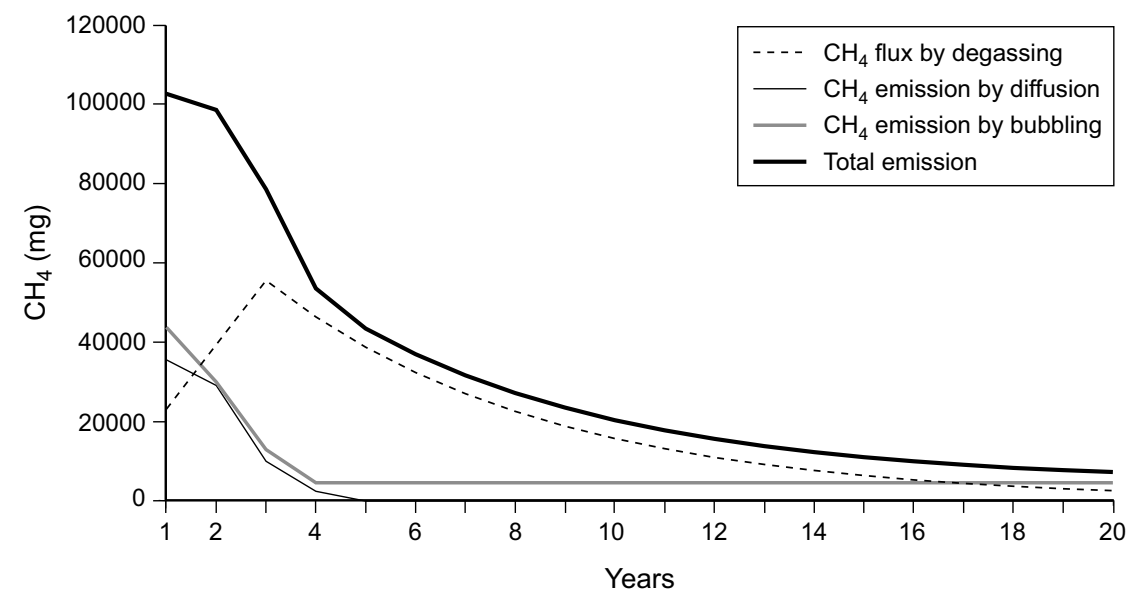

Fig. 12.3. Estimated methane emission trends, over a 20 -year period, from the Petit Saut reservoir 
(P. Gosse et al. 1997). Waterfalls can be naturally present in the river courses of others reservoirs, and the efficiency for water degassing and aeration can be different. However, according to our results, the contribution of the two other emission types, i.e diffusion and bubbling, is important during the first three years after impoundment. This results in maximum total emissions of more than $80 \mathrm{Gg}\left(\mathrm{CH}_{4}\right) \mathrm{y}^{-1}$ for a reservoir of about $365 \mathrm{~km}^{2}$ in which dense equatorial forest was flooded. The overall emission is reduced by a factor of 10 within a 20 -year time frame; this figure is sustained by field measurements taken in similar old reservoirs.

The first estimate of carbon dioxide and methane emissions from the Petit Saut reservoir over a 20-year period relies on field measurements of the various fluxes taken at Petit Saut, and on extrapolations based on the temporal pattern of average dissolved methane concentrations established from Petit Saut and Ivory Coast data an on the relationship between methane and carbon dioxide. Diffusive and bubbling fluxes were measured during experimental campaigns at Petit Saut. $\mathrm{CO}_{2}$ diffusive flux increased to up to $5 \mathrm{~g} \cdot \mathrm{CO}_{2} \cdot \mathrm{m}^{-2} \cdot \mathrm{d}^{-1}$ after impoundment at the beginning of 1995 and then it showed seasonal variations related to dissolved gas concentrations driven by the lake dynamics. This flux did not display the same decrease as methane flux since $\mathrm{CO}_{2}$ is not consumed by bacteria but only by photosynthesis in the euphotic layer. Profiles of dissolved $\mathrm{CO}_{2}$ concentrations do not show any dramatic decrease in the surface layer as was the case in the $\mathrm{CH}_{4}$ profiles. However, the net emission into the atmosphere depends directly on the difference in partial pressure between the water surface layer and the atmosphere and wind stress, and is obviously affected by concentration changes in water. Because of the limited set of measurements of $\mathrm{CO}_{2}$ compared to $\mathrm{CH}_{4}$, the long term evolution of average $\mathrm{CO}_{2}$ concentration in water is deduced from the methane as the two parameters are linearly correlated with a regression coefficient $r=0.92$ (see Eq. 12.2).

Two types of results were derived from the above considerations: a carbon balance of the reservoir 20 years after reservoir filling (Table 12.1) and a comparison between greenhouse gas emissions from the reservoir and from thermal alternatives.

\section{Carbon Budget of the Reservoir}

The carbon losses from the reservoir in the form of both $\mathrm{CO}_{2}$ and $\mathrm{CH}_{4}$ over 20 years are dominated by the outlet flux of dissolved gases $(2160 \pm$ $400 \mathrm{Gg}(\mathrm{C})$ ). The diffusive emission at the lake surface represents $1300 \pm$ $300 \mathrm{Gg}$ (C), whereas emission of gas bubbles is much less important $(130 \pm 35 \mathrm{Gg}(\mathrm{C}))$. The inlet flux of dissolved $\mathrm{CO}_{2}(440 \pm 90 \mathrm{Gg}(\mathrm{C}))$ must 
Table 12.1. Carbon balance of the hydroelectric reservoir of Petit Saut 20 years after reservoir filling

\begin{tabular}{llll}
\hline Type of emission & $\begin{array}{l}\mathrm{CH}_{4} \\
\mathrm{Gg} \mathrm{CH}_{4}\end{array}$ & $\begin{array}{l}\mathrm{CO}_{2} \\
\mathrm{Gg} \mathrm{CO}_{2}\end{array}$ & $\begin{array}{l}\text { Released carbon } \\
\mathrm{CC}=\mathrm{C}-\mathrm{CH}_{4}+\mathrm{C}-\mathrm{CO}_{2} \\
\mathrm{Gg} \mathrm{C}\end{array}$ \\
\hline Emission by diffusion & $77 \pm 10$ & $4700 \pm 1000$ & $1300 \pm 300$ \\
Emission by bubbling & $166 \pm 46$ & $75 \pm 15$ & $145 \pm 40$ \\
Outlet flux & $450 \pm 170$ & $6500 \pm 1000$ & $2160 \pm 400$ \\
Inlet flux & 0 & $-1600 \pm 340$ & $-440 \pm 90$ \\
\hline Total & $693 \pm 226$ & $9675 \pm 2300$ & $3200 \pm 800$ \\
\hline
\end{tabular}

be deduced from the loss terms. The total carbon loss from the reservoir over 20 years, in the form of volatile carbonaceous species is estimated to be $3.2 \mathrm{Tg}(\mathrm{C})$. We estimated the carbon pool from the total amount of organic matter submitted to decomposition in the Petit Saut reservoir to be $270 \mathrm{Mg}(\mathrm{C}) \mathrm{ha}^{-1}$, that is about $10 \mathrm{Tg}(\mathrm{C})$ for the entire reservoir. The carbon loss calculated is about one third of the initial carbon pool and represents certainly the main part of the biodegradable fraction of the submerged organic matter. The remaining part corresponds to the lignin-containing fraction of tree trunks, big branches and roots which decomposes over tens to hundreds of years in anaerobic conditions (Junk \& Nunes de Mello, 1987).

\section{Comparison of GHG Emissions from the Reservoir and from Thermal Alternatives}

The data base obtained from the measurements taken between 1994 and 1999 at Petit Saut was used to estimate the long term impact of a tropical reservoir on the additional greenhouse effect in comparison with thermal alternatives for electric energy production. Temporal variations of greenhouse gas emissions from the Petit Saut reservoir were estimated over a 100 -year period. These emissions were calculated in equivalent $\mathrm{CO}_{2}$ using the concept of GWP (Global Warming potential) as detailed in Delmas et al. (2001). These emissions are highest in the three first years after impoundment and then decrease exponentially following the Eq. 12.1 representing the time evolution of dissolved methane concentration in the reservoir. Cumulated emissions at the end of the period reach $42.3 \mathrm{MT} \mathrm{CO}_{2 \mathrm{eq}}$.

To calculate greenhouse gas emissions from equivalent (115 MW) thermal power plants, we used emissions factors of three greenhouse gases $\left(\mathrm{CO}_{2}, \mathrm{CH}_{4}, \mathrm{~N}_{2} \mathrm{O}\right)$ for oil, coal and natural gas combustion. Calculations are made over a period of 100 years with a methane GWP varying with time and with a constant GWP value (290) for $\mathrm{N}_{2} \mathrm{O}$. Emissions are dominated by $\mathrm{CO}_{2}$ for the three plant types, although significant contributions of ni- 
trous oxide $(12 \%)$ for coal combustion, and of methane $(24 \%)$ for gas combustion are observed. As expected, the gas power plant (64.3 MT $\mathrm{CO}_{2 \text { eq }}$ ) appears to be the 'cleanest' in terms of greenhouse effect in comparison with oil (77.4) and coal (98.2) plants. The comparison between reservoir and thermal power plants is shown on Fig. 12.5. At 100 years, GHG emissions from the reservoir appear to be less than those of either type of thermal alternatives. The figure shows that, due to high emissions following impoundment, the reservoir is a greater emitter in the three first decades, and a smaller one during the last decades, as reservoir emissions decrease. According to these curves, the equivalence between the hydroelectric reservoir of Petit Saut and thermal power plants would occur after 25 years for coal, 35 years for oil, and 57 years for gas plants. Although uncertainties in these calculations are very large our results show that, in spite of a low ratio between energy produced and flooded area, GHG emissions from the Petit Saut reservoir after 100 years, are lower, but of the same order of magnitude as emissions from equivalent thermal alternatives.

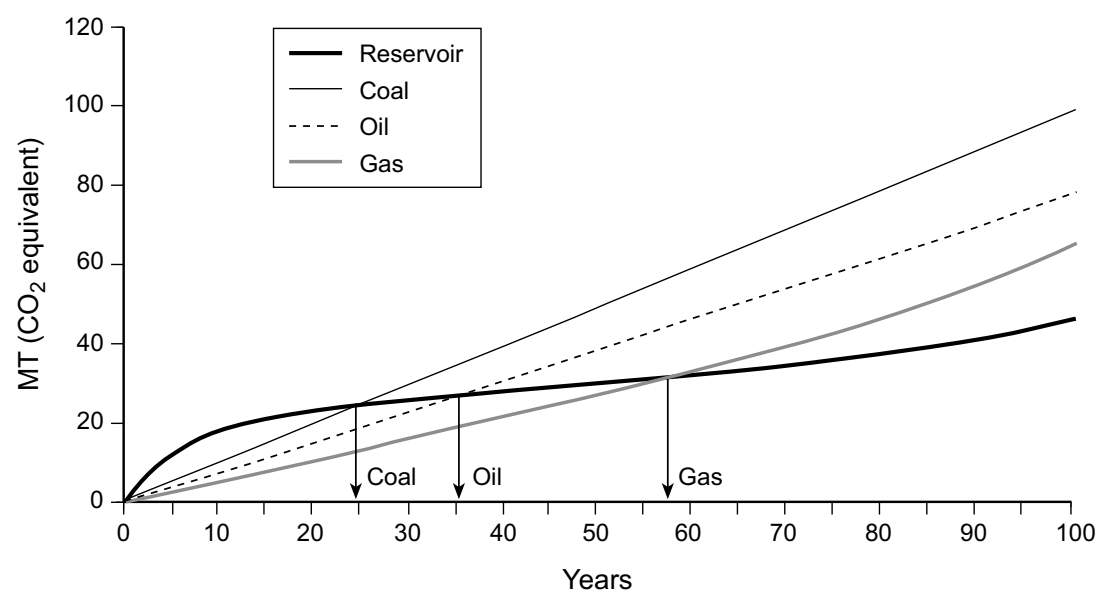

Fig. 12.4. Comparison of cumulative GHG emission at a 100-year time-scale, from the Petit Saut reservoir and of emission from equivalent (115 MW) thermal power plants (coal, oil, and gas)

Gross GHG emissions from the reservoir over its expected lifetime (100 years), are estimated at $42.3 \mathrm{MT}\left(\mathrm{CO}_{2}\right.$ eq $)$ (Fig. 12.5). After 20 years, the emission trend adopted (constant and rather low emissions) is not sustained by observations and is thus subject to large uncertainties. Net reservoir GHG emission calculations that take into account natural emissions from soil and vegetation suppressed after impoundment (6.2-18.1 MT) will 


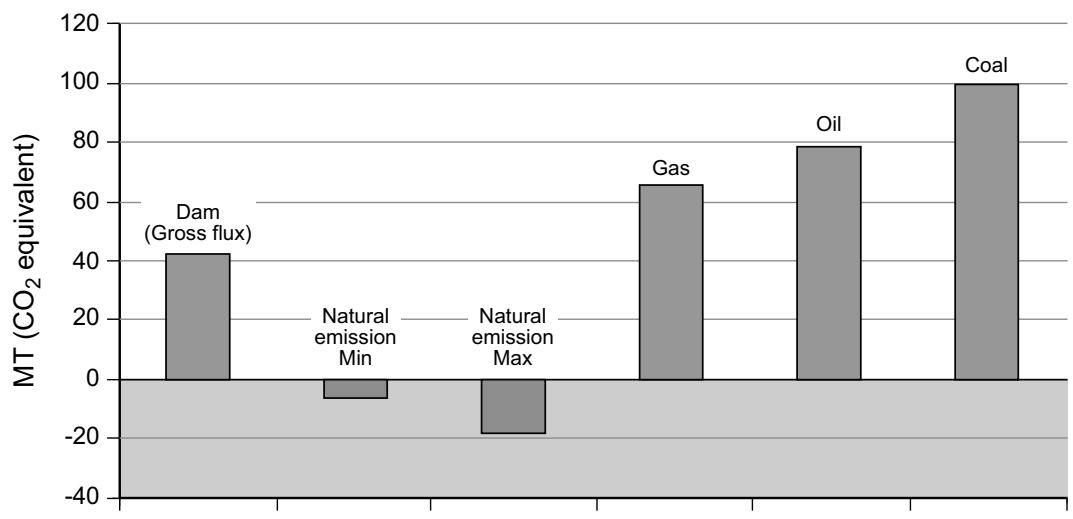

Fig. 12.5. Comparison of greenhouse gas emissions on a 100 -year time-scale of Petit Saut reservoir of natural emissions from soils and of emissions from thermal alternatives

thus range between 24-36 of $\mathrm{CO}_{2 \text { eq }}$ with an average value of $30 \mathrm{MT}$ of $\mathrm{CO}_{2 \mathrm{eq}}$. However, it is assumed that, when comparisons between dam and thermal power plants are made dam energy production over the 100-year period is always highest corresponding to the nominal power of the station $(115 \mathrm{MW})$. The installed capacity of a dam represents what would be generated if all turbines were operated year-round, during about $8700 \mathrm{~h}$, with a maximum water level of the reservoir $(35 \mathrm{~m})$, and in the absence of the aerating weir. This would represent an energy production of about $1 \mathrm{TWh}$ per year. Energy production under real conditions of functioning is regulated by energy demand and reservoir capability. However greenhouse gas emissions from the reservoir remains the same whatever the level of energy production, while emissions from thermal power plants follow its variations. If we assume that, on average over a long period, the energy production from the dam only corresponds to $50 \%$ of the installed capacity, this would reduce the emissions from corresponding thermal alternatives by a factor of two. The comparison between dam and thermal power plants must be based on net greenhouse gas emissions from the reservoir which are about $30 \mathrm{MT} \mathrm{CO}_{2 \text { eq. }}$ With this figure, the average greenhouse gas emissions in equivalent $\mathrm{CO}_{2}$ over a 100 -year period are $0.60 \mathrm{~kg} / \mathrm{kWh}$ for the dam, $0.77,0.98$, and $0.64 \mathrm{~kg} / \mathrm{kWh}$ for oil, coal and gas power plants respectively.

In spite of large uncertainties linked to the extrapolations of emission trends over a 100-year period, it seems that a reservoir such as Petit Saut, where the ratio between installed capacity and inundated area is low, is equivalent or better in terms of greenhouse gas emissions than any thermal 
alternatives. Over a 100 -year period GHG emission from the dam is estimated to be approximately the same as emission from a gas power plant and may be less than emissions from oil and coal plants.

\subsubsection{Long Term Data and Recent Flux Measurements}

Results presented in the previous sections have already been published (Delmas et al. 2001; Galy-Lacaux et al. 1997, 1999). In this section we examine new results of long term observations of methane profiles measured on a monthly basis between 1994 and 2003. We also use data from an experiment conducted in May 2003 to evaluate the fate of gas fluxes throughout the whole hydro-system, from the river upstream of the reservoir to the Sinnamary river mouth in the Atlantic, eight years after reservoir filling. These new data allow some comparisons to be made with predicted emissions previously published (Delmas et al. 2001).

Changes in average methane concentrations in the water column and of water residence time in the reservoir from 1995 to 2003 are shown on Fig. 12.6a along with the modeled variations published several years earlier. The comparison between modeled and experimental concentrations shows that the expression correctly reproduces the mean trend. Seasonal variations are however underestimated. The decrease of methane in the reservoir is due to a reduction of the available biodegradable carbon pool initially immerged, while seasonal variations are linked to reservoir dynamics since water residence time is governed by rainfall pattern and water resource management as explained in Sect. 12.3.1. The water residence time is simply calculated on a monthly basis as the ratio of the reservoir volume to the outflow. This figure confirms the interpretation presented in Sect. 12.3.1: an increase in the water outflow leads to a decrease in the residence time and is followed, within a month, by a decrease in methane concentration. The delayed correlation between water residence time and methane concentration is maximum $(\mathrm{r}=0.48)$ for $\mathrm{dt}=1$ month (Fig. 12.6b). This occurs during the rainy season with significant differences from year to year according to rainfall variations; the sinusoidal variation is clearly a rough approximation of the reality, however, the methane trend over the 8 years of measurements is close to the modeled trend. Furthermore, it was shown in Richard et al. (Chap. 23) that using the sinusoidal function gives rather acceptable results for the methane fluxes from the dam with adequate values of monthly flow discharges. This sustains our previous extrapolation trends based on the modeled trend. However, the comparison between modeled and experimental concentrations of methane and flow discharges within the reservoir and at its outlet allows a 


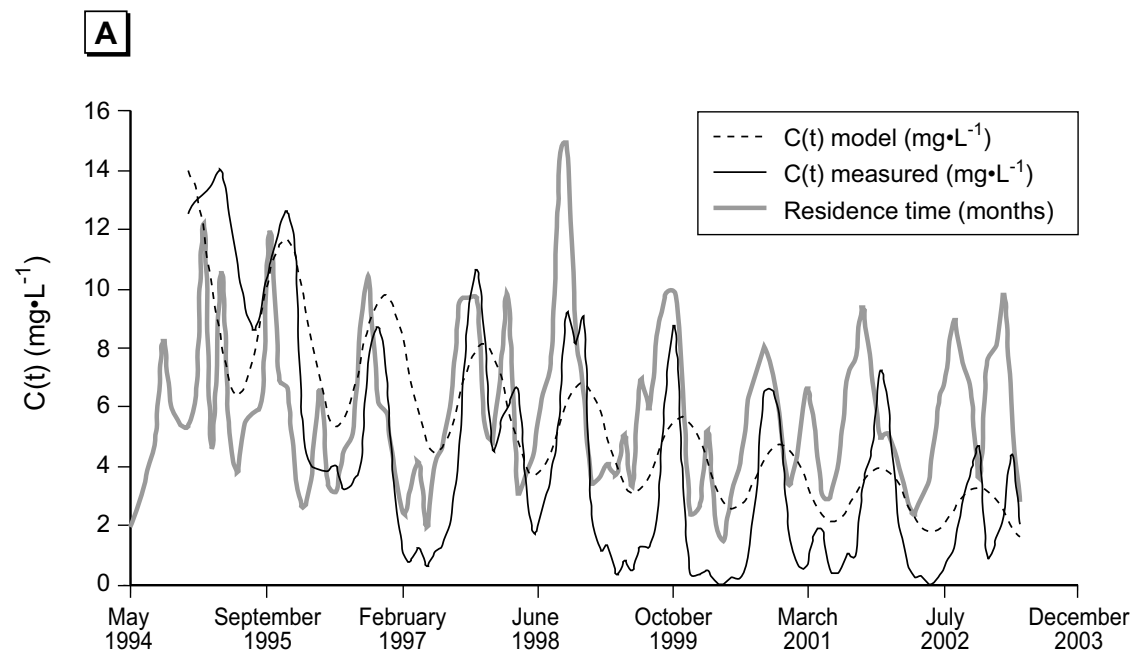

Fig. 12.6a. Evolutions of average methane concentrations in the water column and of water residence time in the reservoir calculated from the daily hydrologic budget of the reservoir, from 1995 to 2003, and comparison with model simulation

\section{B Correlation}

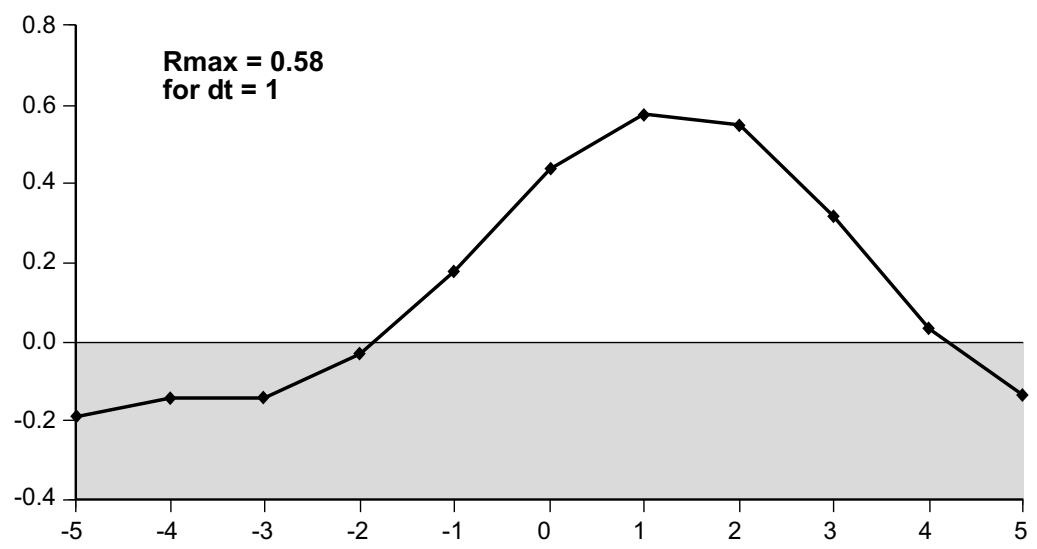

Fig. 12.6b. Delayed correlation between methane concentration and water residence time within the reservoir

more quantitative assessment of the three most important terms of the calculated carbon budget of the reservoir over 20 years (Table 12.1). These terms are the emissions of $\mathrm{CH}_{4}$ and $\mathrm{CO}_{2}$ by degassing at the dam outlet and the $\mathrm{CO}_{2}$ emission by diffusion at the lake surface. Richard et al. (Chap. 22) showed that downstream emissions of $\mathrm{CH}_{4}$ over the first 9 years were pre- 
viously overestimated by probably one third in the previous long term GHG forecasts, due to the representativity of the sinusoidal function and a too schematic yearly profile of flow discharges. Although the $\mathrm{CO}_{2} / \mathrm{CH}_{4}$ ratio in the turbined water has become lower than previously selected (see Chap. 22), there should not be an overestimation of more than $30 \%$ for the previous forecasts of downstream $\mathrm{CO}_{2}$ emissions, as the May 2003 campaign reveals that in the downstream Sinnamary, there is a high level of $\mathrm{CO}_{2}$ emissions to the atmosphere which can be linked to the degradation of non volatile compounds released by the dam. As the downstream GHG fluxes are dominant in the budget, it means that previously calculated greenhouse gas emissions from the reservoir over 100 years might be some $20 \%$ lower than previously assessed. However, it appears that the $\mathrm{CO}_{2}$ emission by diffusion at the lake surface might have been underestimated as it was still high in 2003.

Flux data obtained in May 2003, and shown in Table 12.2, confirm that diffusive methane emissions at the surface are quite low (less than $100 \mathrm{mg}$ $\mathrm{CH}_{4} \cdot \mathrm{m}^{-2} \cdot \mathrm{d}^{-1}$ ) while $\mathrm{CO}_{2}$ fluxes remain significant (around $5000 \mathrm{mg} \cdot \mathrm{m}^{-2} \cdot \mathrm{d}^{-1}$ ). Flooded forest sites emit twice as much $\mathrm{CH}_{4}$ as sites located on the Sinnamary river bed. Surface wind has a strong influence on diffusive flux to the atmosphere, fluxes increase by a factor of 2 for wind speeds greater than $3 \mathrm{~m} \cdot \mathrm{s}^{-1}$. On the upstream river, $\mathrm{CH}_{4}$ fluxes are very low $\left(6 \mathrm{mg} \cdot \mathrm{CH}_{4} \cdot \mathrm{m}^{-2} \cdot \mathrm{d}^{-1}\right)$ whereas $\mathrm{CO}_{2}$ fluxes are two to three times higher than on the lake (4522 on the lake and $13000 \mathrm{mg} \cdot \mathrm{CO}_{2} \cdot \mathrm{m}^{-2} \cdot \mathrm{d}^{-1}$ on the upstream river). Downstream of the dam $(<50 \mathrm{~km})$, fluxes are enhanced by a factor of 9 to 10 for both gases. $\mathrm{N}_{2} \mathrm{O}$ fluxes remain constant in the whole system. We must note that chamber measurements on a water surface may underestimate diffusive emissions during high wind periods, because of the exclusion of natural turbulence at the air-water interface within the chamber, however, the turbulence in the water surface layer is little affected by the chamber (Kremer et al. 2003). This effect on average fluxes is difficult to quantify, since wind is generally very low except in the afternoon when thermal effects generate surface winds with velocity up to $8 \mathrm{~m} \cdot \mathrm{s}^{-1}$. In addition rainfall also affects surface layer turbulence (by dissipation of rain drop kinetic energy) and, therefore, air-water gas exchanges (Ho et al. 1997). Flux measurements in the downstream section of the Sinnamary river confirm that gas release downstream of the dam remains an important source of GHG, at least for methane. 
Table 12.2. Results of Greenhouse gas flux measurements on the Petit Saut reservoir and the Sinnamary river in May 2003 (Courtesy from Louis Varflavy and Alain Tremblay, Hydro-Québec

\begin{tabular}{|c|c|c|c|c|c|c|c|c|c|}
\hline \multirow{2}{*}{$\begin{array}{l}\text { Sites } \\
\text { A. Petit Saut Reservoir }\end{array}$} & \multicolumn{3}{|c|}{$\begin{array}{l}\text { Flux } \mathrm{CH}_{4} \text { Flux } \\
\text { Mean, }(\sigma), \mathrm{n} \\
{\left[\mathrm{mg} \mathrm{m}^{-2} \cdot \text { day }^{-1}\right]}\end{array}$} & \multicolumn{3}{|c|}{$\begin{array}{l}\mathrm{N}_{2} \mathrm{O} \text { Flux } \\
\text { Mean, }(\sigma), \mathrm{n} \\
{\left[\mathrm{mg} \mathrm{m}^{-2} \cdot \text { day }^{-1}\right]}\end{array}$} & \multicolumn{3}{|c|}{$\begin{array}{l}\mathrm{CO}_{2} \text { Flux } \\
\text { Mean, }(\sigma), \mathrm{n} \\
{\left[\mathrm{mg} \mathrm{m}^{-2} \cdot \text { day }^{-1}\right]}\end{array}$} \\
\hline & & & & & & & & & \\
\hline All sites & 87 & $(29)$ & 53 & 3.7 & $(2.1)$ & 53 & 4522 & $(1238)$ & 83 \\
\hline Flooded forest sites & 121 & $(28)$ & 20 & 3.7 & $(1.9)$ & 20 & 5302 & $(1060)$ & 28 \\
\hline $\begin{array}{l}\text { Sites on Sinnamary } \\
\text { river bed }\end{array}$ & 66 & $(29)$ & 33 & 3.7 & $(2.3)$ & 33 & 4125 & $(3334)$ & 5 \\
\hline $\begin{array}{l}\text { Sites with average wind } \\
\text { speed }<3 \mathrm{~m} / \mathrm{s}\end{array}$ & 34 & $(10)$ & 36 & 3.2 & $(2.2)$ & 36 & 2943 & $(820)$ & 57 \\
\hline $\begin{array}{l}\text { Sites with average wind } \\
\text { speed }>3 \mathrm{~m} / \mathrm{s}\end{array}$ & 199 & $(68)$ & 17 & 3.9 & $(2.1)$ & 17 & 7985 & $(2157)$ & 26 \\
\hline \multicolumn{10}{|l|}{ B. Synnamary River } \\
\hline Upstream the reservoir & 6 & (2) & 2 & 3.2 & $(2.6)$ & 2 & 13000 & $(459)$ & 2 \\
\hline $\begin{array}{l}\text { Downstream the Dam } \\
(<50 \mathrm{~km})\end{array}$ & 948 & $(264)$ & 12 & 4.4 & $(2.3)$ & 12 & 44140 & $(17030)$ & 21 \\
\hline $\begin{array}{l}\text { Downstream the Dam } \\
(>50 \mathrm{~km})\end{array}$ & 9 & (8) & 8 & 4.1 & $(2.2)$ & 8 & 38020 & (18835) & 11 \\
\hline Estuary & 2 & (3) & 4 & 3.8 & $(0.6)$ & 4 & 16625 & $(10350)$ & 5 \\
\hline
\end{tabular}

Table 12.3 shows the carbon balance of the whole system in May 2003 including inlet fluxes of $\mathrm{CO}_{2}$ and particulate (POC) and dissolved (DOC) organic carbon. The lake surface remains the main source of carbon to the atmosphere due to $\mathrm{CO}_{2}$ fluxes from the water body $\left(450 \mathrm{~T}(\mathrm{C}) \cdot \mathrm{d}^{-1}\right)$. Methane emissions by diffusion from the lake surface $\left(24 \mathrm{~T}(\mathrm{C}) \cdot \mathrm{d}^{-1}\right)$ are almost the same as emissions occurring downstream of the dam including degassing at the aerating weir level and diffusion to the atmosphere along the river. Atmospheric concentrations greater than $1000 \mathrm{ppm}$ were observed in the plume downwind of the aerating weir. We must note that at present, the weir is less efficient for degassing since it was lowered from 5 to $2 \mathrm{~m}$ height (65\% now versus $80 \%$ when it was $5 \mathrm{~m}$ high). The total outlet flux of $\mathrm{C}$ from the reservoir to the atmosphere and the ocean remains, 10 years after impoundment, at least 4 times higher than the inlet flux of $\mathrm{C}$ from the river to the lake, since bubbling flux is missing. The inlet flux of carbon into the reservoir in this period of high waters is $153 \pm 31 \mathrm{~T}(\mathrm{C}) \cdot \mathrm{d}^{-1}$ while the total outlet flux is $709 \pm 175 \mathrm{~T}(\mathrm{C}) \cdot \mathrm{d}^{-1}$. This means that the reservoir is still a net source of carbon to the atmosphere. Without the dam, for an equivalent river length (120 km length and $100 \mathrm{~m}$ width), transfer of $\mathrm{C}$ to the atmosphere would be around $50 \mathrm{t}(\mathrm{C}) \cdot \mathrm{d}^{-1}$. That implies that the initial pool 
Table 12.3. Carbon balance of the whole system (Upstream river, Lake and downstream river) during the May 2003 campaign (high waters). Note that the bubbling flux is missing in this balance. A rough estimate based on a few measurements give $3.67 \pm 0.15 \mathrm{t}(\mathrm{C}) \cdot \mathrm{d}^{-1}$

\begin{tabular}{|c|c|c|c|c|c|}
\hline & & \multirow[t]{2}{*}{ Nature } & \multirow[t]{2}{*}{$\mathrm{T}(\mathrm{C}) / \mathrm{d}$} & \multicolumn{2}{|c|}{ Total $\mathrm{T}(\mathrm{C}) \cdot \mathrm{d}^{-1}$} \\
\hline & & & & $\begin{array}{l}\text { Average } \\
T(C) \cdot d^{-1}\end{array}$ & $\sigma$ \\
\hline \multirow{3}{*}{\multicolumn{2}{|c|}{ Inlet flux ${ }^{2}$}} & $\mathrm{TOC}^{1}$ & 149 & 153 & 31 \\
\hline & & $\mathrm{CO}_{2}{ }^{1}$ & 4 & & \\
\hline & & $\mathrm{CH}_{4}$ & $<0,1$ & & \\
\hline \multirow[t]{10}{*}{ Outlet flux $^{3}$} & Diffusive flux from the lake & $\mathrm{CO}_{2}$ & 450 & 474 & 131 \\
\hline & surface & $\mathrm{CH}_{4}$ & 24 & & \\
\hline & Degasing on the weir & $\mathrm{CO}_{2}(40 \%)$ & 46 & 62 & 6 \\
\hline & & $\mathrm{CH}_{4}(65 \%)$ & 15 & & \\
\hline & Diffusive flux from the down- & $\mathrm{CO}_{2}$ & 60 & 64 & 24 \\
\hline & stream river & $\mathrm{CH}_{4}$ & 4 & & \\
\hline & Export to the estuary & $\mathrm{CO}_{2}$ & 40 & 109 & 14 \\
\hline & & $\mathrm{CH}_{4}$ & 1 & & \\
\hline & & TOC & 54 & & \\
\hline & Total & & & 709 & 175 \\
\hline
\end{tabular}

${ }^{1}$ Data from Richard \& Horeau (1996) and Galy-Lacaux (1996)

${ }^{2}$ Mean river discharge $=265 \mathrm{~m}^{3} \cdot \mathrm{s}^{-1}$

${ }^{3}$ Mean turbined water discharge $=125 \mathrm{~m}^{3} \cdot \mathrm{s}^{-1}$

of $\mathrm{C}$ is still decomposing and participating in the flux to the atmosphere. Fluxes along the river course downstream of the dam are especially high since the water released through the turbines comes from the hypolimnion were $\mathrm{CO}_{2}$ concentrations are enriched by diffusion from the sediment and organic matter degradation in the anoxic hypolimnion and at the oxicanoxic interface. Downstream of the dam, the decomposition of organic matter is enhanced, therefore, a net carbon flux from the Sinnamary river catchments ( $7000 \mathrm{~km}^{2}$ from the source to the ocean) to the coastal ocean is observed.

\subsection{Conclusion and Perspective}

It is now recognized that hydroelectric reservoirs, and more generally all types of artificial reservoirs, are sources of greenhouse gases. Emissions are dominated by $\mathrm{CO}_{2}$ at boreal and probably at temperate latitudes, whereas, at tropical latitudes, methane emission becomes significant. 

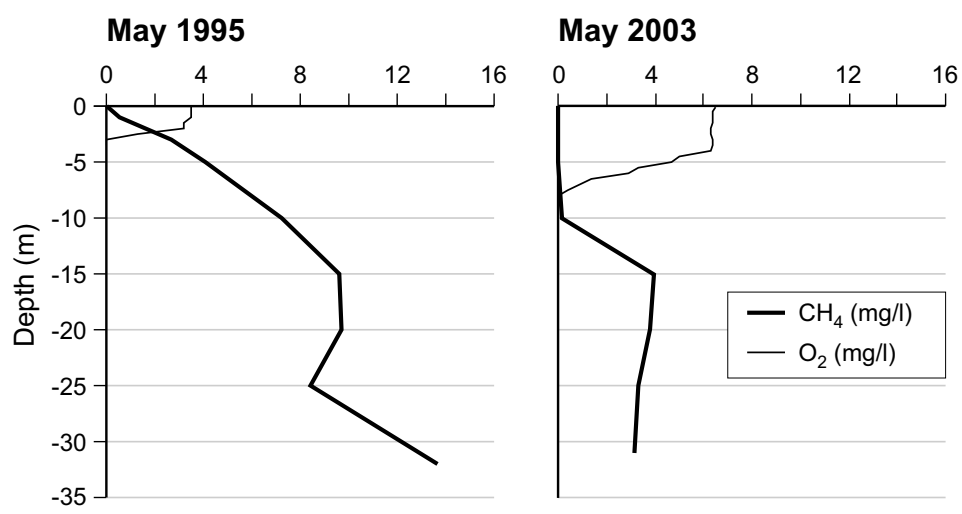

Fig. 12.7. Examples of observed evolution of dissolved methane and oxygen profiles in the water column of the Petit Saut reservoir in May 1995 and May 2003

Concerning artificial reservoirs as a whole, a question remains open: what is the magnitude (even the order of magnitude) of the corresponding methane source? In addition, for any new construction project of a hydroelectric dam it is now necessary to predict more precisely the potential greenhouse gas production to correctly assess the carbon credits linked to the project. It is no longer believed that hydroelectricity is a clean energy, especially in the tropical regions where energy demand is rapidly increasing and potential sites for dam construction are still numerous. However, we should keep in mind that a case by case comparison is necessary since many tropical reservoirs emit very low GHG amounts (Tremblay and Lambert, 2004).

\subsubsection{Future Initiatives}

As it is not possible to carry out field studies everywhere in the world, we decided to start in 2003 a new program based on the development of a reservoir model including the hydrodynamic functioning and the carbon cycle. The model is schematically represented in Fig. 12.8. It will rely first on a 2D finite differences hydrodynamic model with atmospheric and hydrological forcing. This model called SYMPHONIE was developed for coastal oceanography applications and it is adapted to the reservoir, for more details see: Estournel et al. 2001; Auclair et al. 2001. Biogeochemical modules will be coupled to this model; they will describe the potential capacity of the initial stock of organic matter (soil, above ground vegetation, trunks) sequestered during the reservoir filling and of the organic 


\section{RESERVOIR MODEL}

\section{Hydrological forcings}

- $Q_{\mathrm{i}}$ : inlet flow

- $Q_{0}$ : outlet flow

- Qr-Qe : rainfall minus evaporation

\section{Atmospheric forcings}

- $\mathbf{R n}$ : radiation (sensible heat flux)

- $\mathbf{U}^{*}$ : friction velocity (momentum flux)

\section{Gas fluxes}

- inlet/outlet fluxes of dissolved carbonaceous species

- $\mathrm{F}_{1}$ : emission flux $\left(\mathrm{CH}_{4}, \mathrm{CO}_{2}\right)$ at the reservoir bottom,

$\mathrm{P}_{1}$ emission from labile carbon sedimentation

- $\mathrm{F}_{2}: \mathrm{CH}_{4}$ flux above the oxycline (after methane oxidation)

$-\mathrm{F}_{3}$ : diffusive flux $\left(\mathrm{CH}_{4}, \mathrm{CO}_{2}\right)$ at the reservoir surface

$-\mathrm{F}_{4}$ : bubbling flux $\left(\mathrm{CH}_{4}, \mathrm{CO}_{2}\right)$

$-F_{5}$ : flux from degassing at the reservoir outlet

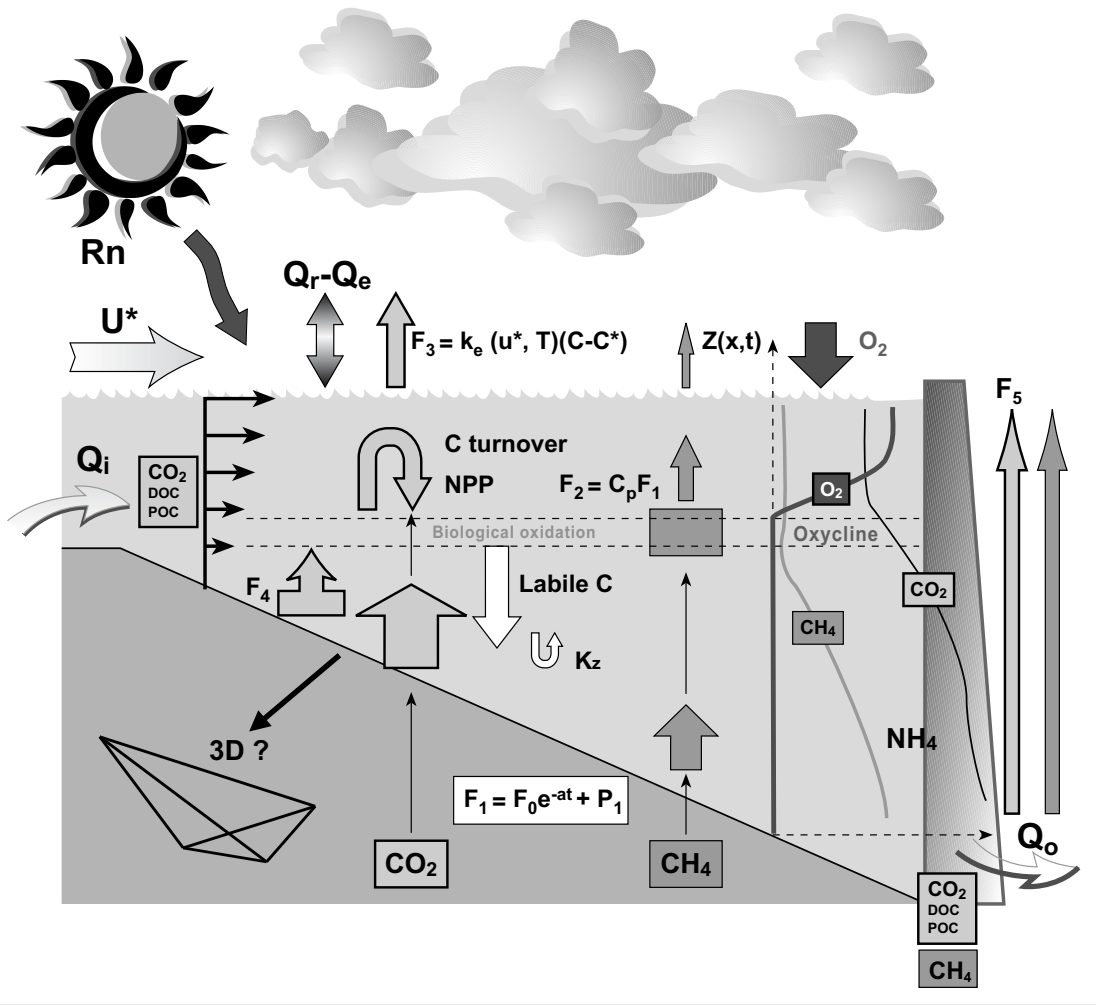

Fig. 12.8. Schematic representation of a $2 \mathrm{D}$ reservoir model to simulate greenhouse gas emissions from a tropical reservoir 
matter (POC, DOC) coming from the river catchments to produce carbon dioxide and methane. The methanogenic activity is determined by anoxic incubations. $\mathrm{CH}_{4}$ and $\mathrm{CO}_{2}$ produced by organic matter degradation in sediments (flooded forest, autochthonous and allochthonous organic matter) diffuse in the water column (Kz: turbulent diffusivity and $\mathrm{F}_{1}$ : molecular diffusion). If methane concentrations are above methane solubility, $\mathrm{CH}_{4}$ is emitted directly in the atmosphere by bubbling in low deep regions of the lake $\left(\mathrm{F}_{4}\right)$. Carbon dioxide and methane produced in the lake sustain a carbon turn-over including sedimentation of labile $\mathrm{C}$ via photosynthesis (Net Primary Production, NPP) and bacterial production (e.g.: methanotrophic activity). The methanotrophic activity will be parameterized thanks to laboratory experiment of methane oxidation. Oxidation rates are determined in laboratory experiments at variable methane concentrations on water samples taken from different depth (oxic epilimnion and oxic-anoxic interface) in order to calculate Kinetics parameters (Michaëlis-Menten). Oxygen necessary for methane oxidation is produced in the lake by photosynthesis or comes from exchanges with atmosphere. The remaining $\mathrm{CH}_{4}$ and the additional $\mathrm{CO}_{2}$ can reach the sub-surface $\left(\mathrm{F}_{2}\right)$. Gas transfer at the air-water interface $\left(\mathrm{F}_{3}\right)$ will be parameterized taking into account surface concentrations and wind speed at $10 \mathrm{~m}$ above the lake surface. Water containing DOC, $\mathrm{POC}, \mathrm{CO}_{2}$ and $\mathrm{CH}_{4}$ reach the estuary passing through turbines. The turbulence induced by the two-fall weir allow a large degassing of methane $(65 \%)$ and carbon dioxide $(40 \%)$ to the atmosphere $\left(\mathrm{F}_{5}\right)$.

In a second step, these modules will be coupled to a 3D finite volume model in order to represent seasonal drawdown and subsequent changes in emissions from the reservoir. A series of new field campaigns is planned in order to derive appropriate parameterizations for modeling and establish the carbon balance of the reservoir 10 years after impoundment.

\section{Acknowledgments}

We are pleased to thank Philippe Gosse (EDF) for disclosing, calculating and writing the main differences between the $\mathrm{CH}_{4}$ and $\mathrm{CO}_{2}$ fluxes downstream of dam over the first 9 years and those previously forecast. Many thank also to Louis Varfalvy and Alain Tremblay (Hydro-Québec) for providing us the complete set of GHG flux measurement taken at Petit Saut during our last campaign in May 2003. 